\title{
A TRAJETÓRIA DE FREDERICO GUILHERME (1897-1972): INTERLOCUÇÕES COM A ESCOLARIZAÇÃO DA EDUCAÇÃO FÍSICA SUL- RIO-GRANDENSE
}

FREDERICO GUILHERME GAELZER'S TRAJECTORY (*1897+1972): INTERLOCATIONS WITH THE SCHOOL OF SUL-RIO-GRANDENSE PHYSICAL EDUCATION

\section{Prof. ${ }^{a}$ Me. Tuany Defaveri Begossi (PPGCMH/ UFRGS) * Prof. a Dra. Vanessa Bellani Lyra (UFRGS) * Prof. ${ }^{\text {a }}$ Dra. Janice Zarpellon Mazo (UFRGS) *}

\section{Resumo}

As pesquisas sobre o professor Frederico Guilherme Gaelzer destacam sua atuação na recreação pública em Porto Alegre/RS e pouco aludem a respeito de seu empenho no desenvolvimento da Educação Física (EF) nas escolas. Diante disso, o presente estudo trata de investigar como ocorreu a atuação de Frederico Guilherme Gaelzer, no cenário da Educação Física escolar sul-rio-grandense, entre as décadas de 1920 a 1940. Para fins deste estudo histórico-documental, além da revisão bibliográfica procedeu-se a análise crítica de documentos. Os materiais de pesquisa manifestaram que Gaelzer foi protagonista na sistematização dos primeiros Cursos Intensivos de EF do estado, os quais visavam à especialização de professoras normalistas para atuação nas escolas primárias do RS. Além disso, inaugurou o cargo de Inspetor de EF no RS, desempenhando papel decisivo na estruturação do campo da EF no estado.

Palavras chaves: História; Educação Física; Frederico Guilherme Gaelzer.

\begin{abstract}
Studies about teacher Frederico Guilherme Gaelzer highlighted his role in public recreation in Porto Alegre/RS and makes little reference to their commitment to the development of physical educaction in schools. Therefore, the present study seeks to investigate how Frederico Guilherme Gaelzer acted in the scenario of school physical education in Rio Grande do Sul, between the 1920s and 1940s. For purposes of this historical-documentary study, in addition to literature review, a critical analysis of documents was carried out. The research materials showed that Gaelzer was protagonist in the systematization of the first Intensive Courses of physical education in the state, which aimed at specializing normal teachers to work in primary schools in RS. In addition, he inaugurated the position of Inspector of physical education in RS, playing a decisive role in structuring the physical education in the state.
\end{abstract}

Keywords: History; Physical Education; Frederico Guilherme Gaelzer.

\footnotetext{
* Doutoranda do Programa de Pós-Graduação em Ciências do Movimento Humano (PPGCMH), na linha de pesquisa Representações Sociais do Movimento Humano, da Escola de Educação Física, Fisioterapia e Dança (ESEFID), da Universidade Federal do Rio Grande do Sul (UFRGS).

* Atualmente é Professora e Coordenadora do Curso de Bacharelado em Educação Física, do Centro Universitário Estácio de Santa Catarina. Pesquisadora do Núcleo de Estudos em História e Memória do Esporte e da Educação Fisica (NEHME) - UFRGS. Pesquisadora do Laboratório de Pesquisa em Atividade Física e Lazer (LAPLAF) - UDESC. Estudante de Pós-doutorado em Ciências do Movimento Humano, pela UDESC (2020).

* Atualmente é Professora Titular da Escola de Educação Física, Fisioterapia e Dança (ESEFID) e do Programa de Pós-Graduação em Ciências do Movimento Humano (PPGCMH), da Universidade Federal do Rio Grande do Sul (UFRGS).
} 


\section{INTRODUÇÃO}

Frederico Guilherme Gaelzer $(* 1897+1972)$, natural da cidade de Novo Hamburgo, então município de São Leopoldo, no Rio Grande do Sul (RS), nasceu em 29 de julho de 1897. A sua família, durante este período, era reconhecida pelo pioneirismo em determinadas áreas. O avô de Frederico, o coronel Gaelzer Netto, por exemplo, foi intendente de São Leopoldo/RS e desenvolveu a infraestrutura da cidade em diferentes âmbitos, sendo distinguido por seu trabalho ${ }^{1}$. Seu pai, por sua vez, se empenhou na promoção de ações que confluíram no crescimento dos clubes da referida cidade. $\mathrm{Na}$ mesma direção de seu avô e pai, o professor Frederico Guilherme Gaelzer teve uma atuação destacada, especialmente, no campo do Esporte e da Educação Física do estado até o seu falecimento, devido a uma embolia pulmonar, no dia primeiro de setembro de 1972.

Durante sua vida profissional, o professor Gaelzer recebeu homenagens de reconhecimento destacando-se, dentre essas, os cartões de agradecimento de exalunos(as) e de instituições como a Young Men's Christian Association (Y.M.C.A.) ${ }^{2}$ de Montevidéu, no Uruguai. Ademais, seu nome foi conferido ao Centro Natatório, da Escola Superior de Educação Física (ESEF), atual Escola de Educação Física, Fisioterapia e Dança (ESEFID), da Universidade Federal do Rio Grande do Sul (UFRGS), onde atuou em diferentes funções durante décadas. Ao mesmo tempo, também fora lembrado ao dar nome a uma Rua, no Bairro Jardim do Salso, em Porto Alegre/RS, conforme Decreto ${ }^{\circ} 16.204$ de 28 de janeiro de 2009, onde presentemente localiza-se a Escola Estadual Fernando Gomes ${ }^{3}$. Ainda, em sua homenagem, o parque localizado na Rua Armando Barbedo s/n, no Bairro Tristeza, em Porto Alegre/RS foi batizado com o nome de Frederico Guilherme Gaelzer ${ }^{4}$.

\footnotetext{
${ }^{1}$ LICHT, Henrique Felippe Bonnet. Henrique Licth II (depoimento 2002). Porto Alegre: Centro de Memória do Esporte - ESEF/UFRGS 2003.

${ }^{2}$ A Y.M.C.A. é a sigla em inglês para a instituição denominada "Associação Cristã de Moços" (ACM), em língua portuguesa. Foi fundada na Inglaterra, em 1844, pela iniciativa de George Williams com a finalidade, na época, de difundir os princípios do cristianismo, através de ações que desenvolvessem o espírito, a mente e o corpo. Posteriormente, irradiou-se para outros países e localidades, onde foram instaladas sedes nacionais e locais. Na América Latina, a primeira ACM foi fundada na cidade do Rio de Janeiro, no final do século XIX. No princípio do século XX, em 1901, foi instalada em Porto Alegre/RS (MAZO, Janice Zarpellon; FROSI, Tiago Oviedo; SILVA, Carolina Fernandes. A Associação Cristã de Moços e a propagação dos esportes em Porto Alegre. Kinesis, Santa Maria, 2012, v. 30, p. 158-173).

${ }^{3}$ VICARI, Paulo Renato. Frederico Guilherme Gaelzer: Protagonista da Educação Física do Rio Grande do Sul. Monografia [Trabalho de conclusão de curso], Escola de Educação Física, Fisioterapia e Dança, Universidade Federal do Rio Grande do Sul, Porto Alegre, 2013.

${ }^{4}$ UTILIDADE PÚBLICA. Parque Frederico Guilherme Gaelzer. Documento, Porto Alegre, 04/03/2004.
} 
No entanto, nos estudos circunscritos na área da Educação Física, o professor Gaelzer é destacado, sobretudo, por seu pioneirismo na recreação pública ${ }^{5}$. Sublinhamos que Gaelzer agenciou uma relação com o poder público de Porto Alegre/RS e o persuadiu sobre a importância da recreação e do esporte para os jovens. Nessa direção, organizou e coordenou ações voltadas à oferta de práticas esportivas e à promoção de eventos esportivos, principalmente, no ambiente não escolar como, por exemplo, nas praças de Porto Alegre/RS. Para além dessas iniciativas foram localizados indícios de que o referido professor também contribuiu no desenvolvimento da Educação Física nas escolas. Todavia, o envolvimento de Gaelzer no processo de escolarização da Educação Física sul-rio-grandense foi, de certo modo, negligenciado nos estudos históricos.

Destarte, a presente pesquisa buscou compreender como ocorreu a atuação do professor Frederico Guilherme Gaelzer no cenário da Educação Física escolar sul-riograndense, entre as décadas de 1920 a 1940. De modo pontual, buscamos investigar as ideias do professor Gaelzer sobre a Educação Física nas escolas do estado, percorrendo os caminhos de sua formação e atuação profissional. A delimitação temporal do estudo aloca, inicialmente, a década de 1920, pois, fora durante este período que as ações de Gaelzer passaram a ser direcionadas, também, ao campo da Educação Física do estado, para além daquelas efetivadas no cenário esportivo e da recreação pública, e se encerra na década de1940, quando Gaelzer atuou na comissão que criou a ESEF, instituição onde foi professor e diretor. Também na década de 1940, Gaelzer contribuiu para a estruturação da Associação dos Especializados em Educação Física e Desportos do Rio Grande do Sul (AEEFD), atual Associação dos Profissionais de Educação Física do Rio Grande do Sul (APEF-RS).

\footnotetext{
${ }^{5}$ WERNECK, Christianne Luce Gomes. Lazer e Estilo de Vida. In: BURGOS, Míria; PINTO, Leila Mirtes S. (Org.). Recreação, lazer e estilo de vida no Rio Grande do Sul: refletindo sobre algumas ações desenvolvidas na capital gaúcha no período 1926-1978. Santa Cruz do Sul: EDUNISC, 2002, p. 95-138; FEIX, Eneida. Lazer e Cidade na Porto Alegre do Início do Século XX: a Institucionalização da Recreação Pública. 2003. Dissertação [Mestrado em Ciências do Movimento Humano], Escola de Educação Física, Fisioterapia e Dança, Universidade Federal do Rio Grande do Sul, Porto Alegre, 2003; PEIXOTO, Elza. O serviço de recreação operária e o projeto de conformação da classe operária no Brasil. ProPosições, Campinas, 2008, vol.19, n. 1, Jan./Abr.,p. 117-133; CUNHA, Maria Luisa Oliveira da. As Práticas Corporais e Esportivas nas Praças e Parques Públicos da Cidade de Porto Alegre (1920-1940). Dissertação [Mestrado em Ciências do Movimento Humano], Escola de Educação Física, Fisioterapia e Dança, Universidade Federal do Rio Grande do Sul, Porto Alegre, 2012; MAYBORODA, Fabiana. Os jardins de recreio em Porto Alegre/RS: uma análise da relação entre a política pública e a constituição de uma educação na República (1920-1950). Dissertação [Mestrado em educação], Universidade do Vale do Rio dos Sinos, São Leopoldo, 2017.
} 
Destacamos que esta investigação passa a ocupar um significativo espaço na trajetória educacional do campo da Educação Física sul-rio-grandense, na medida em que procura (re)posicionar na trama histórica um de seus principais personagens. Em outras palavras, pode-se afirmar que já se tardava o momento de o professor Gaelzer tornar-se foco de análise histórica, no rol das pesquisas acadêmicas. O estudo sobre Frederico Guilherme Gaelzer vem ao encontro do preenchimento de uma lacuna historiográfica que busca ampliar a compreensão de como se constituiu, historicamente, o campo da Educação Física no Rio Grande do Sul.

Para tanto, o presente estudo histórico-documental, amealhou informações obtidas por meio de uma revisão bibliográfica, com a interpretação de documentos operada através da análise crítica de documentos ${ }^{6}$. O referido procedimento busca identificar informações factuais, a partir de questões ou hipóteses de interesse dos pesquisadores. Ato contínuo, procedemos a análise documental propriamente dita, adotado as orientações de Bacellar $(2010)^{7}$, a saber: fichamento, análise e cruzamento das informações.

Após termos realizado a etapa de fichamento, que consiste na elaboração de uma ficha com dados de localização e referência de cada documento, iniciamos a etapa de análise. Neste estágio realizamos um processo de codificação, interpretação e de inferências sobre as informações contidas nos materiais de pesquisa, registrando seu conteúdo manifesto e latente. Por fim, realizamos o cruzamento das informações, ou seja, estabelecemos relações entre as informações localizadas, buscando construir um texto inteligível, organizado em eixos temáticos que emergiram do conteúdo analisado.

Evidenciamos, ainda, para fins metodológicos, que o conjunto de materiais de pesquisa selecionado, integrou livros, jornais, artigos científicos, monografias, dissertações, teses, além do Atlas do Esporte no Rio Grande do Sul e do Banco de dados das Associações Esportivas e de Educação Física de Porto Alegre/Rio Grande do Sul (1867-1945). De outro modo, o grupo de documentos utilizado definiu-se pelos decretoslei, relatórios do Serviço de Recreação Pública de Porto Alegre/RS e cadernos contendo recortes de jornais e anotações, produzidas e preservadas no tempo pelo próprio professor Gaelzer. Buscando alcançar o objetivo anunciado pela investigação, os resultados obtidos

\footnotetext{
${ }^{6}$ LÜDKE, Menga; ANDRÉ, Marli E. D. A. A Pesquisa em educação: abordagem qualitativa. São Paulo: EPU, 1986.

${ }^{7}$ BACELLAR, Carlos. Fontes documentais: uso e mau uso dos arquivos. In: PINSKI, Carla. (Org.). Fontes históricas. 2a Ed. São Paulo: Contexto, 2010, p. 23-80.
} 
por meio da interpretação aos materiais de pesquisa foram organizados nas estruturas textuais que seguem.

\section{O início da trajetória de um professor}

Foi durante sua formação escolar e acadêmica que as escolhas de Gaelzer tornaram visíveis sua crença no poder edificante que atribuía à Educação Física. Sua formação escolar foi bastante diversificada, iniciando-se em 1910, quando cursou a escola primária, no Colégio Nossa Senhora da Conceição, em São Leopoldo/RS. Após a conclusão desse curso, em 1913, foi para Berlim, Alemanha, frequentar o curso secundário no Gymnasium Steglitz. Permaneceu na Alemanha por aproximadamente cinco anos, até o fim da Primeira Guerra Mundial (1914-1918). Talvez, este não fosse o plano inicial de Gaelzer, mas, devido ao conflito mundial e suas implicações no Brasil, prolongou sua estadia na Alemanha. Em particular, no Rio Grande do Sul, os teutobrasileiros foram hostilizados e, muitas vezes, tratados como "inimigos" do Brasil, uma vez que o governo brasileiro se posicionou contra a Alemanha na Primeira Guerra Mundial, posição que se repetiu na Segunda Guerra Mundial (1939-1945). Com relação ao cenário esportivo, o estudo de Mazo $(2007)^{8}$ abordou as ações nacionalizadoras das associações esportivas identificadas com os teuto-brasileiros e, também, ítalo-brasileiros.

Anos depois, em 1918, quando retornou da Alemanha, começou a frequentar a Associação Cristã de Moços (ACM), em Porto Alegre/RS, onde praticava esportes, tais como natação e basquetebol. É um tanto curioso que Gaelzer, em seu retorno ao Rio Grande do Sul, tenha se vinculado a ACM e não a Turnerbund (atual Sociedade de Ginástica Porto Alegre, 1867 - SOGIPA) ou a outra associação esportiva teuto-brasileira. Talvez, isto tenha ocorrido porque a escola onde realizou o curso secundário, na Alemanha, possuía vínculos com as instituições acemistas. Neste mesmo ano e na condição de "acemista" participou do "I Congresso de Educação Física", realizado pela ACM de Buenos Aires/Argentina. Foi também esse vínculo estabelecido com ACM da capital do estado do Rio Grande do Sul que oportunizou a Gaelzer viajar aos Estados Unidos.

8 MAZO, Janice Zarpellon Mazo. A nacionalização das associações esportivas em Porto Alegre (1937-1945). Movimento, Porto Alegre, 2007, v. 13, n.03, p. 43-63, set./dez. 
No referido país, visitou a cidade de Nova York, no período de 5 a 12 de junho de 1919. Em seguida foi atuar como professor da Ray Elementary School, na cidade de Chicago, estado de Illinois. No ano seguinte tornou-se aluno bolsista, sob a matrícula número 2.939, no Campo de Verão, da Young Men's Christian Association (Y.M.C.A.), no George Williams College, em Chicago. Nesta mesma cidade cursou Educação Física, na Universidade de Chicago, sob a matrícula número 83.027, recebendo o título de Master of Science em Educação Física e Recreação, no ano de 1921. Cabe referir, que Gaelzer buscou qualificar sua formação acadêmica para além dos muros da universidade, participando de diferentes eventos e experiências educacionais. Citamos como exemplos desta atitude, a qual se repetiu ao longo de sua vida, a participação no Congresso Continental da Y.M.C.A, em 1918; no Congresso Internacional de Educação Física, na cidade de Detroit (Estados Unidos), em 1919; no Congresso Nacional de Educação Física, em Chicago (Estados Unidos), no ano de 1921; e de uma visita a ACM da cidade do México (México), também em 1921.

De posse do título de Master of Science em Educação Física e Recreação, Gaelzer trabalhou como professor do Y.M.C.A. de Hyde Park, em Chicago. Neste mesmo ano, 1922, após aprovação em concurso de cátedra para "Profissionais das Escolas Superiores do estado da Florida" foi nomeado, sob a matrícula número 1.459, diretor do Departamento de Educação Física, das escolas de Dania, Fort Lauderdale e Miami. No ano seguinte, em 1923, fez o curso de chefe supervisor do Boy Scouts of America e, em 1924, foi colaborar na estruturação do movimento escoteiro no México e, por isso, recebeu a comenda "Cacique Maior", conferida pela organização Tribus Indigenas Mejicanas. Cabe ressaltar que, antes de viajar para o México foi assistir aos Jogos Olímpicos de Verão, realizados em Paris, na França, no período de quatro de maio a 25 de julho de 1924.

Além disso, no caminho de regresso ao Brasil, esteve na ACM de Montevidéu, no Uruguai, onde trabalhou com basquetebol e participou dos programas de recreação pública. Em 1925, já em Porto Alegre/RS, tornou-se membro neutral da Federacion Uruguaya de Basket-ball e representante oficial da Confederacion Sul Americana de Basket-ball, no Brasil. O professor Gaelzer sempre manteve um forte envolvimento com o campo esportivo, como foi possível verificar pelas funções mencionadas acima e por outras que desempenhou ao longo da sua vida como, por exemplo, ter sido membro fundador da "Liga Atlética Porto Alegrense" (LAPA), instalada em 1927 que, posteriormente, mudou o nome para Federação Atlética Rio Grandense (FARG). 
De modo concomitante as suas ações no cenário do esporte e da recreação pública, o professor Gaelzer, no final dos anos 1920, voltou-se para o campo da Educação Física. Deste modo, no ano de 1928, a Educação Física sul-rio-grandense, para além da organização da formação especializada assistiu, por meio da intervenção particular do professor Gaelzer, a organização do primeiro programa de Educação Física, para os colégios elementares e a primeira "Demonstração de Educação Física" da Escola Normal de Porto Alegre/RS, atualmente, Instituto de Educação General Flores da Cunha. A "Demonstração de Educação Física", que consistiu na exibição de exercícios de ginástica pelas alunas normalistas, integrava as comemorações cívicas relativas à data de sete de setembro. Outra atividade organizada pelo professor Gaelzer foi a "Campanha de Ensino da Natação" para os meninos sócios do Grêmio Náutico União9 .

Ainda no cenário da Educação Física, no ano de 1929, o professor Gaelzer inaugurou o cargo de Inspetor de Educação Física, no estado do Rio Grande do Sul, ao ser nomeado para esta função pela Secretaria de Educação, conforme a Portaria no 762 de 26 de fevereiro de 1929, assinada pelo governador do estado Getúlio Vargas. Neste mesmo ano foi nomeado professor de Educação Física da Escola Normal de Porto Alegre, conforme Portaria n 2.744 , de 26 de abril de 1929.

Na condição de professor e inspetor de Educação Física, participou do Congresso de Educação Física e Recreação, realizado na Escola de Educação Física de Charlottemburg, em Berlim (Alemanha), no ano de 1930. O jornal Diário de Notícias ${ }^{10}$ divulgou o que denominou de missão de estudos na Europa do professor. Em seu currículo $^{11}$, ainda consta a participação neste mesmo evento nas cidades de Copenhagen (Dinamarca), Estocolmo (Suécia), Joinville-le-Pont (França) e Hellerau (Luxemburgo). A fim de compreendermos qual fora o papel desempenhado pelo professor Gaelzer no cargo que ocupou cabe-nos, neste momento, reconstituirmos o passado e explanarmos como foram organizadas as estruturas administrativas educacionais do estado de um modo geral e, da Educação Física de modo particular.

\section{Ações pioneiras para a Educação Física sul-rio-grandense}

\footnotetext{
${ }^{9}$ O Grêmio Náutico União é um clube da cidade de Porto Alegre/RS fundado no ano de 1906 para a prática do remo. Ao longo dos anos incorporou outros esportes.

${ }^{10}$ PREPARANDO A RAÇA para um destino melhor. Diário de Notícias, Porto Alegre, 07 out. 1933.

11 CURRICULUM VITAE FREDERICO GUILHERME GAELZER: professor catedrático, professor emérito. Universidade Federal do Rio Grande do Sul. Escola Superior de Educação Física. mimeo, s/d.
} 
Em um exercício de volta no tempo histórico, nos deparamos com o registro datado do ano de 1877, no qual ocorreu a inserção da matéria denominada "Gymnastica, esgrima e exercicios militares", no programa de estudos da Escola Normal, da então denominada Província de São Pedro do Rio Grande do Sul (atual estado do Rio Grande do Sul $)^{12}$. No entanto, os indícios históricos localizados para a construção do presente estudo, nos conduziram a sublinhar que, ainda em 1890, práticas voltadas à educação do corpo permaneciam ausentes das escolas do estado. Nesta direção, podemos deduzir que, neste momento inicial, a inclusão de tais saberes no programa da Escola Normal, voltada a formação de professores(as) primários(as), não representou de modo direto a inserção desta dimensão educacional nas escolas elementares, voltadas à formação inicial dos(as) $\operatorname{alunos}(\text { as })^{13}$.

Novas leis e direcionamentos relacionados a esta matéria sucederam posteriormente, mas, nenhum fora capaz de regulamentar, de fato, o espaço, o tempo e a quem caberia a responsabilidade pelo ensino de tais conteúdos. Dessa forma, percebemos que, neste período, a Educação Física, compreendida enquanto uma educação do corpo, era lecionada por professores(as) de classe, não possuindo caráter científico e nem profissional. Talvez, essa realidade tenha se conformado em razão da inexistência de uma formação específica, voltada ao preparo de professores(as) especializados(as), para atuarem com esse conhecimento nas escolas elementares do estado.

Os registros históricos nos apontam que, aproximadamente até o ano de 1929, os(as) professores(as) preparavam suas sessões de "Gymnastica" - assim denomimada por conta da grafia da época - através de leituras de livros que, geralmente eram oriundos de outros países. Ademais, havia professores(as) que eram sócios(as) da Turnerbund de Porto Alegre/RS, posteriormente, denominada "Sociedade de Ginástica Porto Alegre, 1867” (SOGIPA), onde a ginástica alemã era ensinada. As sessões de ginástica destinadas a homens e mulheres nesta sociedade eram ministradas, algumas vezes, por instrutores

\footnotetext{
12 LYRA, Vanessa Bellani; BEGOSSI, Tuany Defaveri; MAZO, Janice Zarpellon. Da obrigatoriedade do ensino de Educação Física no estado do Rio Grande do Sul (1840-1937). Revista Currículo sem Fronteiras, 2016, v. 16, n. 2, mai./ago. p. 225-241.

13 PICOLLI, João Carlos Jaccottet. A Educação Física na escola pública do Rio Grande do Sul: antecedentes históricos (1857-1984). Pelotas: UFPel, 1994; PICOLLI, João Carlos Jaccottet. A Educação Física escolar no Rio Grande do Sul. In: DACOSTA, Lamartine Pereira da. (Org.). Atlas do Esporte no Brasil. Rio de Janeiro: CONFEF, 2006; LYRA, Vanessa Bellani. A Criação da Escola Superior de Educação Física do Rio Grande do Sul: Formação de professoras(es) para a construção do campo (19401970). Tese [Doutorado em Ciências do Movimento Humano], Escola de Educação Física, Fisioterapia e Dança, Universidade Federal do Rio Grande do Sul, Porto Alegre, 2013.
} 
oriundos da Alemanha ${ }^{14}$.

No ano de 1929, ocorreu uma reformulação dos órgãos que orientavam e organizavam a educação no estado do Rio Grande do Sul, através da promulgação do Decreto Estadual no 4.258, no dia 21 de janeiro de $1929^{15}$. A referida normativa transferiu a administração da instrução pública estadual da Secretaria do Interior para à Diretoria Geral da Instrução Pública. Esta Diretoria, subordinada à Secretaria do Interior, tinha o objetivo de administrar, articular, orientar e, também, fiscalizar o ensino ministrado nas escolas mantidas pelo governo estadual. Tal documento foi inserido na legislação educacional do estado, a partir da autorização do, então presidente do Rio Grande do Sul, Getúlio Vargas.

Talvez, este último aspecto, o da fiscalização do ensino, mereça ser destacado como a peça propulsora deste sentido de inauguração trazido pela criação da nova Diretoria. Além da proposição de uma nova política de formação profissional já anunciada nos documentos anteriores, a inspeção do trabalho pedagógico realizado passou a ser considerada uma medida fundamental aos êxitos do processo no cenário educacional do estado, em termos de sua consolidação nas escolas. Afinal, as novas concepções que passaram a ser adotadas para o campo da Educação sul-rio-grandense certamente não ficaram livres de críticas, disputas e resistências por parte daqueles que há tempos atuavam no magistério e que, por vezes, já estavam habituados com os seus próprios conceitos de Educação e seus modos de fazê-la. Fiscalizar o trabalho docente, nesse sentido, passou a ser considerada parte do processo de implantação de um novo conceito de educação, que se pretendia hegemônico, nas escolas públicas primárias do Rio Grande do Sul.

Sob as ordens de um Diretor Geral, cargo que, naquele momento, era ocupado pelo juiz da comarca de Bento Gonçalves, o bacharel Luiz Freitas e Castro, a Diretoria subdividia-se em três sessões: a Seção Administrativa, a Seção Técnica e o Almoxarifado $^{16}$. Nesse arranjo, a estrutura que mais nos interessou foi a Seção Técnica,

\footnotetext{
${ }^{14}$ BEGOSSI, Tuany Defaveri, MAZO, Janice Zarpellon. Ginástica Alemã e Ginástica Feminina Moderna: práticas destinadas às mulheres. Revista Cinergis, 2015, v. 16, n. 4, p. 306-311, out./dez.

${ }^{15}$ RIO GRANDE DO SUL. Decreto n. 4.258, de 21 de janeiro 1929. Aprova o regulamento da Diretoria Geral da Instrução Pública. Documento do Arquivo Histórico do Rio Grande do Sul. Porto Alegre, RS, p. 237, 1929a.

${ }^{16}$ RIO GRANDE DO SUL. Decreto n. 4.131, de 31 de agosto de 1928. Nomeia o Diretor Geral da Instrução Pública. In: LEGISLAÇÃO: leis, actos e decretos do governo do estado do Rio Grande do Sul. Porto Alegre: [s.n.], 1928.
} 
cuja organização de pessoal se fazia pelas figuras dos inspetores de ensino, responsáveis diretos pela supracitada fiscalização.

A Educação Física, incluída na Seção Técnica da Diretoria Geral, era supervisionada por um inspetor especialmente designado para o cargo que, de modo pioneiro, fora ocupado pelo professor Frederico Guilherme Gaelzer. Muito procurado pelos jornais locais da época, Gaelzer lançava-se pacientemente ao trabalho de receber os jornalistas em seu gabinete e, a partir de longas reportagens, educar a população para um novo olhar sobre o papel da Educação Física na sociedade. Ressalta-se que a Inspetoria de Educação Física tinha como finalidade centralizar a Educação Física, no que tange à administração, elaboração de programas e supervisão desta matéria, nas escolas estaduais do Rio Grande do Sul.

Mesmo que seu espaço e reconhecimento ainda estivessem em construção, há evidências de que a Educação Física passou a ser compreendida como um elemento importante no contexto escolar sul-rio-grandense. Não obstante, o aumento gradativo de carga-horária nos programas das escolas elementares e dos cursos de formação profissional, a criação de uma inspetoria com vistas a vigiar o trabalho que era desenvolvido no interior da matéria de Educação Física revela, entre outras, a preocupação em consolidar, no ambiente escolar, um saber particular que se tornava significativo e, ao mesmo tempo, transmiti-lo adiante com eficácia e eficiência.

Todavia, em termos práticos, emergiu a dúvida sobre as atribuições do inspetor de Educação Física. Assim como aos demais cargos de fiscalização criados pelo Decreto de 1929, ao referido inspetor pontuou-se competências que deveriam ser postas a feito pelo nomeado ao cargo. Essas foram trazidas à tona no Artigo $18^{\circ}$, do mencionado Decreto e pontuavam o seguinte: apresentar, anualmente, ao Diretor Geral, um programa de Educação Física; desenvolver e executar o programa; orientar os professores e inspecionar as escolas; organizar o escotismo nas escolas; propor a aquisição de aparelhos e materiais apropriados à Educação Física ${ }^{17}$. Além de tais encargos, o inspetor deveria elaborar um relatório anual das atividades e apresentar ao Diretor Geral até o dia 15 de janeiro do ano seguinte.

Ainda em 1929, ocorreu a promulgação do Decreto estadual $n^{\circ} 4.277$, no dia 13 de março, que pretendeu regulamentar o ensino normal e complementar do Rio Grande

\footnotetext{
${ }^{17}$ RIO GRANDE DO SUL. Decreto n. 4.258, de 21 de janeiro 1929. Aprova o regulamento da Diretoria Geral da Instrução Pública. Documento do Arquivo Histórico do Rio Grande do Sul. Porto Alegre, RS, p. 237, 1929a.
} 
do Sul. O ensino normal era ministrado pela Escola Normal de Porto Alegre e em escolas complementares localizadas na capital e, também, em cidades do interior do estado. Ademais, destaca-se que, no programa de estudos da Escola Normal, o qual era composto por dois anos de duração, estavam incluídas sessões de Educação Física, com duração de 50 minutos cada ${ }^{18}$. Após um mês da promulgação do mencionado Decreto, a Educação Física foi referida como matéria obrigatória para todos os alunos dos cursos Normal e Complementar do estado.

Diante desse fato, o professor Gaelzer, com o intuito de formular um programa de Educação Física para as escolas complementares, estabeleceu que as finalidades deste saber seriam o desenvolvimento físico e pessoal de cada aluno e o fornecimento de conhecimentos básicos para que os(as) futuros(as) professores(as) demonstrassem competência no ensino da Educação Física. Este plano determinava que as sessões de Educação Física fossem diárias para todos os níveis escolares, sendo duas vezes por semana as aulas ministradas em local interno, espaçoso e em lugar arejado. Quanto ao aspecto recreativo das sessões, seriam realizadas, sempre que fosse possível, ao ar livre.

No que diz respeito aos(as) alunos(as) das escolas complementares do estado, além de serem instigados a praticar Educação Física vestindo uniformes específicos, eram avaliados quanto à excelência do trabalho, melhoria da postura e assiduidade às aulas. Segundo o professor Gaelzer, as aulas de Educação Física deveriam abranger os seguintes tipos de atividades: a) Jogos e folguedos livres e fiscalizados, inclusive as danças (bailados do folclore); b) Atividades atléticas fiscalizadas e livres; c) Escoteirismo e outras atividades semelhantes, tanto para as meninas como para os meninos; d) Exercícios formais ou ginásticos propriamente ditos; e) Ginástica ortopédica, terapêutica e médica; f) Piqueniques, excursões e raids escolares; g) Demonstrações culturais de postura e ginástica $^{19}$.

O programa de Educação Física, elaborado pelo professor Gaelzer, para as escolas complementares foi, provavelmente, a primeira iniciativa com o objetivo de unificar o ensino desta matéria, em todas as escolas complementares do estado, na década de 1920. No referido programa, quando analisado de modo mais minucioso, torna-se notória também, a presença de algumas atividades de procedência estrangeira, tais como o

\footnotetext{
${ }^{18}$ RIO GRANDE DO SUL. Decreto-lei n. 4.277 de 13 de março de 1929. Provê sobre o ensino Normal e Complementar do Estado. Documento do Arquivo Histórico do Rio Grande do Sul. Porto Alegre, RS, [s.n.], $1929 \mathrm{~b}$.

${ }^{19}$ GAELZER, Frederico Guilherme. Correspondência enviada ao Diretor Geral da Instrução Pública, 28 mar. 1930.
} 
newcomb (jogo introdutório ao voleibol), cageball (jogo pré-esportivo com bola), voleibol e basquetebol. A inclusão de tais atividades, nas aulas de Educação Física das escolas complementares do estado foi, provavelmente, influenciada pelo fato de o professor Gaelzer ter permanecido, conforme já evidenciado no presente estudo, aproximadamente, cinco anos nos Estados Unidos, onde tais esportes já se adiantavam na prática.

Os conhecimentos obtidos e as experiências vividas por Gaelzer nos Estados Unidos, foram gradativamente sendo aplicados ao ensino da Educação Física no Rio Grande do Sul. Percebe-se que havia uma preocupação em instrumentalizar adequadamente o(a) futuro(a) professor(a) de primeiro grau, para que pudesse ministrar novas aulas de Educação Física à infância escolarizada. A partir de ideias como essa, o professor Gaelzer foi se destacando e desempenhando um papel decisivo para a estruturação da Educação Física no Rio Grande do Sul.

A preocupação do professor Gaelzer parecia não se limitar apenas a Educação Física nas escolas, mas, também, no que diz respeito a organização da categoria profissional. Nesta direção, fez parte do grupo que fundou a "Associação Rio Grandense dos Professores de Educação Physica", instalada no ano de 1930, na capital, Porto Alegre/RS. Esta entidade tinha o intuito de estabelecer a união do professorado sul-riograndense para que, neste arranjo, fosse tratado o desenvolvimento da matéria de Educação Física. A “Associação Rio Grandense dos Professores de Educação Physica" emergiu com a reunião de forças de sua primeira diretoria, a saber: "Prof. Guilherme Gaelzer, presidente; Prof. ${ }^{\text {a }}$ Zilda Pinto, vice-presidente; Amelia Porto Alegre, primeira secretária; Hilda Silveira, segunda secretária e, Maria Elna Tufvesson, thesoureira"20. Percebe-se que, com exceção da presidência, todas as demais funções eram desempenhadas por mulheres. Gaelzer assumiu o desafio de se tornar o primeiro presidente da referida entidade e, assim, conduzir a construção das embrionárias estruturas organizacionais, em prol da regulamentação da profissão de "professor de Educação Física", ainda incipientes no estado.

$\mathrm{Na}$ liderança da entidade que buscava fortalecer o(a) professor(a) de Educação Física e já reconhecido pela sua atuação no âmbito da recreação pública, por meio da (re)significação das praças públicas enquanto espaço de jardins de recreio, prática de

\footnotetext{
${ }^{20}$ PELO APERFEIÇOAMENTO da nossa raça. Diário do Povo, Porto Alegre, p. 25, 4 fev. 1930.
} 
esportes e de Educação Física, o professor Gaelzer coordenou a "Semana da Raça"21. Esta foi a primeira iniciativa de caráter cívico escolar realizada no Brasil, cunhada pelo governo do estado do Rio Grande do Sul, no ano de $1933^{22}$. Constituiu-se numa festividade cívica, realizada em Porto Alegre/RS, envolvendo professores(as) e alunos(as) das escolas. Guiado pelos mesmos objetivos que motivou a "Semana da Raça", em 1938 o professor Gaelzer foi presidente da comissão organizadora da "Semana da Pátria”, cujas comemorações continham programas cívicos sociais e desfile de escolares, na capital do estado. As ações de Gaelzer, em diferentes funções, denotaram seu compromisso com o campo da Educação Física, mas, sem perder de vista a necessidade de também investir na formação profissional.

\section{A sistematização da formação de professoras}

A criação dos chamados Cursos Intensivos de Educação Física ou Cursos de Aperfeiçoamento para professores(as) de ensino fundamental do estado foi estabelecido através do Decreto-Lei n ${ }^{\circ}$ 4.277, de 13 de março de 1929. O referido Decreto-Lei também determinou que essa formação fosse realizada nos meses de janeiro e fevereiro (período de férias escolares), na Escola Normal de Porto Alegre/RS. Os Cursos Intensivos de Férias, na ausência de instituições que formassem professores(as) de Educação Física no estado, tinham o objetivo de atualizar e preparar professores(as) normalistas e/ou complementaristas para ministrarem aulas de Educação Física nas escolas estaduais de primeiro grau (ensino fundamental).

O primeiro Curso Intensivo de Educação Física foi promovido pela iniciativa do professor Gaelzer, no mesmo ano de sua criação legal, 1929, quando ocupava o cargo de Inspetor de Educação Física. Este Curso teve o apoio da Diretoria Geral da Instrução Pública. As aulas iniciaram no dia seis de novembro, às 16 horas, junto a sede da Inspetoria estadual de Educação Física, nas dependências do Colégio Elementar Paula Soares, em Porto Alegre/RS. Além disso, consta que o referido curso funcionava todas as quartas-feiras e aos sábados, das $16 \mathrm{~h}$ às 18 horas $^{23}$. Logo, no começo do ano de 1930,

\footnotetext{
${ }^{21}$ MAYBORODA, Fabiana. Os jardins de recreio em Porto Alegre/RS: uma análise da relação entre a política pública e a constituição de uma educação na República (1920-1950). Dissertação [Mestrado em educação], Universidade do Vale do Rio dos Sinos, São Leopoldo, 2017.

${ }^{22}$ Sobre a "Semana da Raça" no Rio Grande do Sul, sugere-se a leitura do livro de CARLAN, Paulo. A Educação Física Escolar em Ijuí, de 1933 a 1941: a Semana da Raça. Ijuí/RS: Editora UNIJUí, 1998.

${ }^{23}$ GAELZER, Frederico Guilherme. Correspondência enviada ao Diretor da Instrução Pública do estado,
} 
ocorreu o segundo Curso Intensivo, cuja conclusão se deu dia 28 de março de 1930, formando nove professoras ${ }^{24}$. Após a conclusão, as professoras foram indicadas pelo Inspetor de Educação Física, o professor Gaelzer, para atuarem nos colégios complementares Paula Soares, Fernando Gomes, Voluntários da Pátria, Souza Lobo, Glória, Partenon, 13 de Maio, Tristeza e na Escola Normal de Porto Alegre ${ }^{25}$.

Já o terceiro Curso Intensivo teve como preocupação disseminar conhecimentos nas mais diversas áreas da Educação Física. Na referida edição o Curso apresentou os seguintes conteúdos: 1) Educação Fisica contemplando História; Metodologia (enfocando divisão de uma aula e exercícios calistênicos) e Filosofia; 2) Corpo Humano contemplando Biografia (evolução); Anatomia (estrutura em geral); Fisiologia (respiração e sistema nervoso); Fisiologia do exercício (efeitos do exercício sobre a respiração, circulação e sistema neuromuscular); Higiene (asseio pessoal, banho, alimentação, descanso, ambiente, a postura, o álcool e o fumo); 3) Organização e Administração nas escolas (programas horários, pátios, monitores, formação de grupos, times e clubes); nos Jardins de Recreio (programas de atividades, divisão das idades, concursos de suficiência); nos clubes (organização de uniões, federações de esportes; jogos organizados como voleibol, basquetebol, hoquei, base e tênis); nos campeonatos (denominados relâmpago, eliminação, e turnos); 4) Recreação Pública nos Jardins de Recreio (propaganda, material, plantas, administração); 5) Jogos organizados (livres e em massa); 6) Bailados do folclore; 7) Natação (aprendizado pelo método "confiança", saltos, salvamento e aperfeiçoamento ${ }^{26}$.

A realização dos Cursos Intensivos fez com que se despertasse o interesse de administradores educacionais do estado, pelo ensino da Educação Física nas escolas estaduais de ensino fundamental. A obrigatoriedade do ensino da Educação Física, provavelmente, não fora implementada na época devido a ausência de uma formação especializada de professores(as) e mesmo de instituições específicas voltadas a este fim. Foram os Cursos Intensivos, portanto, que deram o primeiro impulso para que a obrigatoriedade da Educação Física, nas escolas estaduais de ensino fundamental, fosse

17 de outubro de 1929.

${ }^{24}$ PELO APERFEIÇOAMENTO da nossa raça. Diário do Povo, Porto Alegre, p. 25, 4 fev. 1930.

${ }^{25}$ GAELZER, Frederico Guilherme. Correspondência enviada ao Diretor Geral da Instrução Pública, 28 mar. 1930.

${ }^{26}$ LYRA, Vanessa Bellani. A Criação da Escola Superior de Educação Física do Rio Grande do Sul: Formação de professoras(es) para a construção do campo (1940-1970). Tese [Doutorado em Ciências do Movimento Humano], Escola de Educação Física, Fisioterapia e Dança, Universidade Federal do Rio Grande do Sul, Porto Alegre, 2013. 
cumprida.

No começo do ano de 1936, do dia dois de janeiro até o dia 15 de fevereiro, foi realizada mais uma edição do Curso Intensivo de Educação Física, ainda sob a responsabilidade do professor Gaelzer. Este curso preparou 21 professores(as) normalistas ou com diploma de Curso Complementar, para o ensino da Educação Física nas escolas estaduais de primeiro grau. É importante salientar que havia requisitos que os(as) interessados(as) deveriam preencher antes de serem selecionados(as) para o curso, dentre os quais citamos a idade mímima de 18 e máxima de 30 anos e a apresentação de diploma de conclusão do curso complementar ou equivalente ${ }^{27}$.

No dia em que se encerrou o Curso Intensivo - 15 de fevereiro de 1936 - um grupo de professores(as) que o frequentaram, como forma de agradecimento ao professor Gaelzer pelo esforço e dedicação, e com o objetivo de demonstrar algumas atividades aprendidas, fizeram uma apresentação de ginástica, jogos e dança. A apresentação, que ocorreu antes da entrega dos diplomas aos(as) participantes do Curso, contava com o seguinte programa: "apresentação com marchas, exercícios livres, jogo de cara e coroa, exercícios com bastões, bailado Tarantela, exercícios com halteres, jogo de relevo do tacape, bailado As de Ouro, exercícios com tacapes e Jogo do Tacape-ball (parecido com o atual jogo de taco $)^{28}$. Estavam presentes no evento autoridades, entre elas, o Secretário dos Negócios da Educação e Saúde Pública do estado, Otelo Rosa, o Diretor da Instrução Pública, Professor Guerreiro Lima, familiares e amigos(as) dos(as) formandos(as). Esta edição do Curso Intensivo ocorrida no ano de 1936 foi a útima que localizamos registros.

Muitas professoras que frequentaram os cursos foram distribuídas pelo Inspetor de Educação Física, da Diretoria Geral de Instrução Pública do estado entre várias escolas, principalmente, aquelas localizadas em Porto Alegre/RS. É interessante destacarmos ainda, a massiva presença de mulheres compondo o quadro de alunas em formação. Esta característica reforça a questão de feminização do magistério sul-rio-grandense, tão destacado no referido período. Após o encerramento do Curso Intensivo e das homenagens pelo trabalho desenvolvido na formação de professoras, ainda no ano de 1936, o professor Gaelzer representou o Brasil no II Congresso Internacional de Recreação, realizado na cidade de Hamburgo (Alemanha). Nesta ocasião foi eleito membro do Conselho Consultivo Mundial de Recreação. É provável que tal experiência

\footnotetext{
${ }^{27}$ CURSOS DE EDUCAÇÃO FÍSICA. Diário de Notícias. Porto Alegre, 16 de fevereiro de 1936, s/p.

28 CURSOS DE EDUCAÇÃO FÍSICA. Diário de Notícias. Porto Alegre, 16 de fevereiro de 1936, s/p.
} 
tenha contribuído para a formulação dos novos arranjos empreendidos nas futuras disposições da formação do professorado do estado. Depois deste evento, Gaelzer também foi para Berlim assistir os Jogos Olímpicos de $1936^{29}$.

Nos anos seguintes, com a instauração no Brasil, do período conhecido como Estado Novo (1937-1945) e a eclosão da segunda Guerra Mundial (1939-1945), a formação de professores(as) Educação Física sofrera mudanças e influências significativas. O Governo Federal, pelo Decreto n ${ }^{\circ} 1.212$ de 17 de abril de 1939, passou a exigir formação profissional específica para o exercício das profissões de professor de Educação Física, Técnico Desportivo e Médico Especializado Educação Física e Desportos. Vale ressaltar que o Decreto assinalou a preocupação das autoridades educacionais em fazer com que somente os(as) professores(as) normalistas, especializados(as) em Educação Física fossem contratados(as) para ministrarem aulas nas escolas estaduais de primeiro grau, no território brasileiro.

Em decorrência de tal legislação, ainda no ano de 1939 foi instalada a Escola Nacional de Educação Física e Desportos (ENEFD), da Universidade do Brasil, atualmente, Universidade Federal do Rio de Janeiro (UFRJ) ${ }^{30}$. A ENEFD foi considerada Escola modelo, a partir da qual outras instituições de preparação de professores(as) de Educação Física que viriam a ser criadas deveriam orientar suas ações ${ }^{31}$. Com a criação desta instituição emergiu, também, a necessidade, na época, de se determinar um método de Educação Física a ser seguido, aspecto este que desencadeou grandes discussões. Embora tenha sido motivo para duras críticas da Associação Brasileira de Educação, o Método Francês foi adotado pela ENEFD. Por consequência desta atitude, instituições encarregadas da formação de professores(as) de Educação Física, estabelecidas após a ENEFD, também adotaram o Método Francês como norteador de suas ações educacionais. O posterior declínio na utilização do Método Francês foi desecadeado após as autoridades educacionais brasileiras realizarem severas revisões dos aspectos anatômicos, fisiológicos e psicológicos da Educação Física no país. Tal avaliação foi

\footnotetext{
${ }^{29}$ Alguns materiais reunidos pelo professor Frederico Guilherme Gaelzer, nos Jogos Olímpicos de Berlim, em 1936, foram doados ao Centro de Memória do Esporte (CEME), da Escola de Educação Física, Fisioterapia e Dança (ESEFID), da Universidade Federal do Rio Grande do Sul (UFRGS). A busca pode ser realizada através do Repositório Digital do CEME: http://www.lume.ufrgs.br/handle/10183/40501.

${ }^{30}$ BRASIL. Decreto n. 1212 de 17 de abril de 1939. Dispões sobre a criação da Escola Nacional de Educação Física e Desportos. Diário Oficial da União, Rio de Janeiro, seção 1, p. 49, 17 abr. 1939.

${ }^{31}$ LYRA, Vanessa Bellani; MAZO, Janice Zarpellon. Escola Superior de Educação Física do Rio Grande do Sul: De um modelo nacional ao protagonismo de um modelo estadual. Educação e Fronteiras, 2016 , v. 6, n. 18 , set./dez.
} 
ocasionada pela rendição da Linha Maginot, composta por um milhão de soldados franceses, causando uma decepção mundial ${ }^{32}$.

No Rio Grande do Sul, o Método Francês foi criticado pelas autoridades educacionais. O professor Gaelzer, na época, Inspetor de Educação Física, da Diretoria Geral da Instrução Pública do estado, assumia-se enquanto árduo seguidor do Método Sueco de Ginástica, a qual era preconizada por Per Henrik Ling, um dos maiores críticos do Método Francês. Gaelzer concedeu, em 1939, uma entrevista a um jornal de Porto Alegre expressando seu desejo de que o Método Francês não fosse adotado pela ENEFD. Esta manifestação contrária ao Método Francês ocasionou a sua demissão da Inspetoria de Educação Física do estado ${ }^{33}$.

Embora, afastado da Inspetoria, o professor Gaelzer continuou envolvido com a Educação Física. No final do ano de 1939, quando foi apresentada a proposta de criação do Departamento estadual de Educação Física, o nome dele constava entre os colaboradores. Juntamente com o Departamento foi viabilizado o projeto de criação da ESEF, por deliberação do, então Secretário de Educação do estado do Rio Grande do Sul, José Pedro Coelho de Souza, atendendo à determinação do Interventor Federal no Rio Grande do Sul, General Oswaldo Cordeiro de Farias. Para Diretor do Departamento e da ESEF foi nomeado, com licença do Ministro da Guerra, o capitão Olavo Amaro da Silveira. O núcleo inicial da ESEF era formado pelo Diretor-Fundador e os professores: Waldir Calvet Echart, João Gomes Moreira Filho, Max Herbert Hanke e Frederico Guilherme Gaelzer ${ }^{34}$.

O professor Gaelzer figurou no corpo docente pioneiro da ESEF, que entrou em funcionamento no dia seis de maio de 1940. Mencionamos que a ESEF foi a primeira instituição estabelecida no Rio Grande do Sul, com objetivo de formar professores(as) de Educação Física. No princípio, oferecia os seguintes cursos: Curso Normal de Educação Física, com duração de um ano e Curso Superior de Educação Física, com duração de

\footnotetext{
${ }^{32}$ MARINHO, Inezil Penna. História da educação física e desportos no Brasil: Brasil colônia, império e república. Rio de Janeiro: Revista dos Tribunais, 1952.

33 PICOLLI, João Carlos Jaccottet. A Educação Física na escola pública do Rio Grande do Sul: antecedentes históricos (1857-1984). Pelotas: UFPel, 1994; PICOLLI, João Carlos Jaccottet. A Educação Física escolar no Rio Grande do Sul. In: DACOSTA, Lamartine Pereira da. (Org.). Atlas do Esporte no Brasil. Rio de Janeiro: CONFEF, 2006.

${ }^{34}$ LYRA, Vanessa Bellani; MAZO, Janice Zarpellon. A Escola Superior de Educação Física e o campo da formação de professores do estado sul-rio-grandense: as origens da formação especializada (1869-1929). Revista Movimento, Porto Alegre, 2010, v. 16, p. 53-75; BEGOSSI, Tuany Defaveri. A construção dos saberes disciplinares do Curso Normal da Escola Superior de Educação Física do estado do Rio Grande do Sul (1940-1956). 2017. Dissertação [Mestrado em Ciências do Movimento Humano], Escola de Educação Física, Fisioterapia e Dança, Universidade Federal do Rio Grande do Sul, Porto Alegre, 2017.
} 
dois anos ${ }^{35}$. Segundo Lyra $(2013)^{36}$, Gaelzer atuou como professor auxiliar na disciplina de Desportos Aquáticos, cujo responsável era o segundo tenente Nelson Rocha, e também era o professor responsável pela disciplina de Ginástica de Aparelhos de Pesos e Halteres. Para além das funções de ensino, conforme determinação da Portaria $n^{\circ} 875$, de 28 de fevereiro de 1944, Gaelzer também foi designado para integrar o Conselho Técnico Administrativo da ESEF. Passada mais de uma década, o professor assumiu o cargo de diretor da Escola, no período de 28/09/1955 a 24/02/1959 ${ }^{37}$. O seu trabalho foi reconhecido pela instituição, uma vez que o professor Gaelzer dá nome ao Centro Natatório da ESEFID ${ }^{38}$.

Ressaltamos que o professor Gaelzer também foi um dos fundadores da Associação dos Especializados em Educação Física e Desportos do Rio Grande do Sul (AEEFD), atual Associação dos Profissionais de Educação Física do Rio Grande do Sul (APEF-RS). A organização desta entidade, conforme os registros de Licht $(2005)^{39}$, começou com um movimento de professores(as) da ESEF, liderados por Frederico Guilherme Gaelzer e Jacintho Francisco Targa, desencadeado nos meses de agosto e setembro de 1945. Tais professores foram apoiados por Maurício Akcelrud, Inspetor Federal de Educação Física na época, que defendia a fundação de uma entidade de classe, para congregar professores(as), técnicos e médicos especializados em Educação Física e Desportos, do estado do Rio Grande do Sul.

Após alguns meses, no dia 20 de dezembro de 1945, nas dependências da ESEF, foi realizada uma reunião de professores de Educação Física, presidida pelo Diretor da instituição, o capitão Olavo Amaro da Silveira, na qual se deliberou pela fundação da

\footnotetext{
${ }^{35}$ RELATÓRIO DO GENERAL OSVALDO CORDEIRO DE FARIAS, Interventor Federal do Rio Grande do Sul, ao Presidente do Estado, Getúlio Dornelles Vargas, durante o período de 1938-1943. Porto Alegre: Oficinas Gráficas da Imprensa Oficial, 1943.

${ }^{36}$ LYRA, Vanessa Bellani. A Criação da Escola Superior de Educação Física do Rio Grande do Sul: Formação de professoras(es) para a construção do campo (1940-1970). Tese [Doutorado em Ciências do Movimento Humano], Escola de Educação Física, Fisioterapia e Dança, Universidade Federal do Rio Grande do Sul, Porto Alegre, 2013.

${ }^{37}$ GUTIERREZ, Washington. Diagnóstico das Escolas de Educação Física do Estado do Rio Grande do Sul. 1946. Dissertação (Mestrado), Escola de Educação Física, Universidade Federal do Rio Grande do Sul, Porto Alegre, 1976.

${ }^{38}$ MAYBORODA, Fabiana. Os jardins de recreio em Porto Alegre/RS: uma análise da relação entre a política pública e a constituição de uma educação na República (1920-1950). Dissertação [Mestrado em educação], Universidade do Vale do Rio dos Sinos, São Leopoldo, 2017.

${ }^{39}$ LICHT, Henrique Felippe Bonnet. Centro Esportivo da Beira Rio: subsídios históricos. Documento produzido por Henrique Licht que autorizou publicação no Repositório Digital do Centro de Memória do Esporte (CEME), da Escola de Educação Física, Fisioterapia e Dança (ESFID), da Universidade Federal do Rio Grande do Sul (UFRGS). 2005. Disponível em: http://hdl.handle.net/10183/71063. Acesso em: dezembro de 2020.
} 
AEEFD/RS, bem como pela eleição de sua diretoria provisória. Nesta primeira diretoria, o professor Gaelzer ocupou o cargo de secretário cultural ${ }^{40}$. A entidade era encarregada, entre outros atributos, de assegurar os direitos contidos em lei; promover o intercâmbio entre médicos, professores(as) de Educação Física, técnicos e massagistas esportivos; trabalhar para firmar o conceito dos especializados em Educação Física no meio educacional; além de colaborar com todas as instituições legalmente constituídas no sentido de obter maior divulgação da Educação Física.

\section{Considerações Finais}

A abordagem histórico-documental do presente estudo lançou-se ao desafio de contribuir para o avanço das investigações afeitas à área da formação de professores(as), ao interpretar a atuação do professor Frederico Guilherme Gaelzer, no cenário da Educação Física sul-rio-grandense. A análise dos documentos históricos sobre os quais nos debruçamos revelou, na postura desse professor, um protagonismo de ações, que alocaram a Educação Física do sul do país e na vanguarda do cenário educacional nacional. Todavia, tal protagonismo não significa uma ação individual do professor Gaelzer, mas, sim, um lugar de destaque em um tempo e espaço, dentre os atores que construíram o campo da Educação Física.

Quanto ao papel desempenhado pelo professor Gaelzer frente à Educação Física, podemos mencionar sua atuação decisiva nas ações pioneiras que confluíram na formação/especialização de professores(as) da área, atuando como Inspetor de Educação Física e organizador dos primeiros Cursos Intensivos, no estado do Rio Grande do Sul. Ainda, podemos lembrar que o professor colaborou, em comissão, no projeto de criação da ESEF, atual Escola de Educação Física, Fisioterapia e Dança (ESEFID) da UFRGS, onde foi professor e diretor. Gaelzer também contribuiu para a conformação da AEEFD, atual Associação dos Profissionais de Educação Física do Rio Grande do Sul (APEF-RS).

A liderança proveniente do professor Gaelzer, conforme registravam os jornais da época, foi essencial para a Educação Física conquistar um espaço na escola sul-riograndense. As propostas empreendidas por Gaelzer foram viabilizadas em um cenário que favoreceu suas ações. Era uma época em que as práticas corporais e esportivas

\footnotetext{
40 MARTINI, Sérgio; ONZI, Vanessa; MAZO, Janice Zarpellon. Associação dos Especializados em Educação e Desportos do Rio Grande do Sul - AEEFD/RS: percorrendo os caminhos de sua criação. Revista Digital - Buenos Aires, 2010, año 15, n. 144, mai.
} 
ganhavam impulso por diferentes motivos. Na cidade de Porto Alegre/RS, desde a segunda metade do século XIX, práticas foram institucionalizadas em associações, principalmente, organizadas pela iniciativa de imigrantes alemães. No começo do século $\mathrm{XX}$, por sua vez, houve a disseminação de ideias que valorizavam as práticas esportivas. Vale lembrar, ainda, que Gaelzer frequentou clubes, mas, particularmente, envolveu-se fortemente com a ACM de Porto Alegre/RS, a qual se estabeleceu estando interligada a outras no Brasil e articulada com uma rede mais ampla na América Latina, Estados Unidos e outros países, sob a tutela da Y.M.C.A.

Desta forma, podemos afirmar que havia condições postas para o desenvolvimento da Educação Física e dos esportes nos clubes, escolas e, posteriormente, nas praças públicas. Foi este contexto que, provavelmente, permitiu a Gaelzer tornar-se um protagonista. Entretanto, é sabido que, embora tenha se destacado no campo da Educação Física, do esporte e da recreação pública, conseguiu empreender muitas ações em razão de colaboradores que, muitas vezes, permanecem invisibilizados pelos documentos oficiais, por não ocuparem cargos políticos de destaque. Gaelzer, provavelmente, contou com uma rede de pessoas como, por exemplo, os membros da comissão de criação da ESEF e os(as) professores(as) desta instituição, quando se tornou diretor.

Data de submissão: 02/02/2021

Data de aceite: 20/12/2021. 